\title{
A MERENDA NO DIA ALIMENTAR DE CRIANÇAS MATRICULADAS EM CENTROS DE EDUCAÇÃO E ALIMENTAÇÃO DO PRE-ESCOLAR*
}

\author{
Rosa Nilda Mazzilli**
}

\begin{abstract}
MAZZILLI, R. N. A merenda no dia alimentar de crianças matriculadas em Centros de Educação e Alimentação do Pré-Escolar. Rev. Saúde públ., S. Paulo, 21:317-25, 1987.
\end{abstract}

RESUMO: Estudou-se o papel da merenda no comportamento alimentar de 346 pré-escolares (PE) matriculados em Centros de Educação e Alimentação do Pré-Escolar (CEAPEs) de seis municípios do Estado de São Paulo, Brasil. Em entrevista domiciliar com a mãe ou responsável pela alimentação do $\mathrm{PE}$, obteve-se o número e a quantidade dos alimentos ingeridos pela criança antes e após sua participação no CEAPE. Verificou-se que essa refeição escolar interfere tanto na quantidade dos alimentos consumidos quanto no número das refeições diárias feitas no lar. Os resultados mostraram que $178(51,4 \%)$ PE reduziram a ingestão alimentar de casa, mediante exclusão de refeições e/ou diminuição da quantidade de alimentos habitualmente ingerida, após receberem a merenda no CEAPE. Destas, $115(64,6 \%)$ apresentaram dieta insuficiente em energia; 48 (13,9\%) aumentaram a quantidade dos alimentos habituais e/ou incluíram refeições. Ainda assim, 23 (47,9\%) apresentaram consumo energético deficiente. Entre os $120(34,7 \%)$ que não tiveram nenhuma modificação em seu dia alimentar, $61(51,7 \%)$ mostraram ingestão calórica inadequada. Concluiu-se ser necessário orientar a família sobre o papel da merenda como suplemento alimentar e não como substituto de refeições no lar.

UNITERMOS: Alimentação escolar. Pré-escolares. Hábitos alimentares. Conduta na alimentação. Ingestão calórica. Educação nutricional.

\section{INTRODUÇÃO}

A assistência alimentar à criança que vai à escola tem sua origem no século passado. Durante a Revolução Francesa, em 1791, foi inaugurado, na França, o primeiro serviço de distribuição de merenda ${ }^{16}$. Nos Estados Unidos da América do Norte, a partir de 1853, iniciou-se a distribuição voluntária de alimentos nas escolas vocacionais e, posteriormente, em 1894 , surgiram os primeiros programas de alimentação nas escolas municipais ${ }^{13}$.

No Brasil, a assistência alimentar nas escolas também foi empreendimento voluntário de comunidade, promovido, inicialmente, pelos contribuintes da "Caixa Escolar", hoje Associação de Pais e Mestres ${ }^{13}$.

A "sopa escolar" constituiu a primeira forma de suplementação alimentar; era preparada nas residências das famílias e transportada até as escolas. Nessa época, entretanto, não havia a preocupação com o estado nutricional da criança que recebia o alimento, pois, a desnutrição protéico-energética - DPE, deficiência só identificada na década de 30 , ainda não se definia como tal. $O$ que se pretendia era minimizar a fome das crianças que chegavam à escola sem ter ingerido qualquer alimento ${ }^{13}$.

Em 1954 foi criada a "Comissão Nacional de Alimentação" (CNA) com a finalidade de racionalizar os Programas de Merenda Escolar - PME - existentes e, ao mesmo tempo, de ampliar sua ação às regiões ainda não beneficiadas ${ }^{12}$. No ano seguinte, em seu lugar, surgiu a Campanha de Merenda Escolar (CME), órgão subordinado ao Ministério da Educação e Cultura (MEC).

No Estado de São Paulo, em 1945, com a criação da Seção de Nutrição no Serviço de Saúde Escolar, vinculado à Secretaria de Educação do Estado, a assistência alimentar, até então desenvolvida empiricamente em algumas escolas, tomou novas diretrizes ${ }^{15}$. A partir de 1947 foi instituído o PME, pelo esforço e dedicação de um grupo de nutricionistas, preo-

* Parte da Tese de Doutorado intitulada "Contribuição e Interferência da Merenda Escolar no Dia Alimentar de Crianças Matriculadas em Centros de Educação e Alimentação do Pré-Escolar - CEAPEs", apresentada à Faculdade de Saúde Pública da Universidade de São Paulo, em 1984.

*:* Departamento de Nutrição da Faculdade de Saúde Pública da Universidade de São Paulo - Av. Dr. Arnaldo, 715 - 01255 - São Paulo, SP — Brasil. 
cupadas com a situação alimentar do escolar. Posteriormente, as atividades de educação alimentar, desenvolvidas por esse grupo de especialistas, despertaram o interesse das autoridades ligadas ao ensino, as quais apoiaram esse trabalho com doações orçamentárias para atender à merenda nas escolas.

Em 1957, após convênio realizado com a CME, as atividades da Seção de Nutrição do Serviço de Saúde Escolar estenderam-se por todo o interior do Estado de São Paulo, dando maior importância e destaque ao PME*.

No Município de São Paulc, as atividades de assistência alimentar datam de 1935, visando, especificamente, aos pré-escolares que frequientavam os parques infantis. A partir de 1960 esse benefício estendeu-se também às escolas municipais.

Em 1967, a Prefeitura de São Paulo firmou o primeiro Convênio com o CNAE, o que facilitou a ampliação da merenda a todos os alunos matriculados na Rede Municipal de Ensino, sem distinção de seu nível econômico ${ }^{15}$.

Em 1972, pela Lei Federal $5.829 / 72$, foi criado o Instituto Nacional de Alimentação e Nutrição (INAN), autarquia vinculada ao Ministério da Saúde, com a finalidade de estabelecer as diretrizes para a Política Nacional de Alimentação e Nutrição, consolidadas no Programa Nacional de Alimentação e Nutrição (PRONAN) ${ }^{8}$. Faz parte do PRONAN o Programa Nacional de Alimentação Escolar (PNAE), que objetiva "proporcionar suplementação alimentar aos escolares de $1 .^{\circ}$ grau, matriculados nos estabelecimentos oficiais e filantrópicos de ensino e a pré-escolares".

Após quase vinte e sete anos de existência, a CNAE, pela Portaria 708 de 22/12/81**, transformou-se no Instituto Nacional de Assistência ao Estudante (INAE), órgão que tem como finalidade assegurar os instrumentos $\mathrm{e}$ condições de assistência ao educando. O INAE, hoje fundação (FNAE), entidade de caráter normativo, atua de forma descentralizada, responsável pela programação, financiamento e avaliação dos programas de apoio ao estudante, com prioridade nos níveis de formação pré- escolar e escolar de primeiro e segundo graus a serem desenvolvidos nos Estados e Municípios do País.

Sendo um dos objetivos básicos do PNAE, ligados à assistência alimentar, "a melhoria da qualidade, a diminuição dos custos e a criação de melhores condições de acesso dos usuários à alimentação escolar", é fundamental a avaliação do Programa no sentido de se averiguar o quanto está sendo eficiente e eficaz à sua população-alvo.

A análise da literatura específica sobre o consumo alimentar do pré-escolar, grupo etário de interesse desta pesquisa, mostrou que os estudos dietéticos individuais são mais escassos do que aqueles que avaliam a ingestão de alimentos em nível familiar, pela maior dificuldade na obtenção dos dados, considerando que a alimentação é preparada para toda a família. Essa dificuldade aumenta quando se procura avaliar o consumo alimentar de crianças, pois exige cooperação e boa vontade da mãe ${ }^{14}$.

As investigações sobre a alimentação de pré-escolares freqüentemente estão relacionadas ou com a ingestão da família ou com nível sócio-econômico ${ }^{2,3,4,5,11}$, não se verificando associação com a merenda escolar e sua interferência no dia alimentar da criança, exceção para o estudo de Beaton e Ghassemi ${ }^{1}$. Como se pode depreender, os levantamentos sobre consumo alimentar de pré-escolares enfocam outros aspectos, exceção da pesquisa de Beaton e Ghassemi; em nenhum deles houve a preocupação de analisar a interferência da suplementação alimentar, sob a forma de merenda, na alimentação diária de pré-escolares, ou de averiguar se esse suplemento substitui refeições que a criança recebe em seu lar.

$O$ presente trabalho objetiva investigar a interferência da merenda escolar na alimentação diária de pré-escolares matriculados em Centros de Educação e Alimentação do Pré-Escolar (CEAPEs) ${ }^{* * *}$, sob os seguintes aspectos:

- modificações no comportamento alimentar em relação à quantidade dos alimentos servidos ao pré-escolar - PE, antes e após frequientar regularmente o CEAPE;

- se a merenda servida no CEAPE suplementa ou substitui refeições que a criança consome no lar.

* CARVAlHo, C. S. e PEReirA, V. B. de L. Aspectos conceituais do Programa de Merenda Escolar, São Paulo, Secretaria de Educação - Departamento de Assistência Escolar, Divisão de Estudos, Normas e Programas de Nutrição. Dados inéditos.

** Diário Oficial da União, 24 de dezembro, 1981. Seção I, p. 24.785-89.

*** Informaçōes sobre os objetivos e atividades dos CEAPEs podem ser encontrados em Gandra ${ }^{6,7}$ (1973, 1981). 


\section{POPULAÇÃO DE ESTUDO}

A população estudada foi constituída pela totalidade de pré-escolares de 2 anos completos a 7 incompletos de 26 CEAPEs, implantados em 6 cidades do interior paulista.

Para obtenção da amostra considerou-se:

a - o conjunto de crianças matriculadas em CEAPEs, de uma mesma cidade, representou um domínio de estudo;

b - cada conjunto de pré-escolares da população de estudo, matriculados em CEAPEs de uma mesma área, representou um conglomerado de crianças.

Identificados os domínios de estudo e os conglomerados de crianças, foi selecionada a amostra, empregando-se a amostragem probabilística em 3 etapas; o local foi a unidade amostral na primeira etapa, a família na segunda e o pré-escolar na terceira etapa. A amostra ficou constituída por 346 crianças, cuja distribuição, por sexo e cidades, está apresentada na Tabela 1.

\section{MÉTODO}

Os dados referentes ao comportamento alimentar das crianças, quanto as refeiçōes consumidas em casa, foram fornecidos pela mãe ou responsável direto por sua alimentação, em visita domiciliar. Durante a entrevista, solicitou-se informações quanto ao número de refeições diárias e a quantidade de alimentos habitualmente ingeridos em cada uma delas, antes e após a matrícula do PE, no Programa. As modificações apresentadas pelo pré-escolar, quanto as refeições e quantidade de alimentos, foram então comparadas, relacionando-as, posteriormente, com a ingestão individual da criança, referente apenas à energia, dados esses existentes de pesquisa realizada no mesmo grupo de crianças 9 .

\section{RESULTADOS E COMENTÁRIOS}

A avaliação dos programas de suplementação alimentar tem sido, de modo geral, em termos de cobertura da população-alvo. E importante conhecer a abrangência do programa em relação à meta estabelecida, mas é fundamental, também, saber se o suplemento ofere-

TABELA 1

Distribuição dos pré-escolares estudados, segundo sexo e cidades do Estado de São Paulo, $1978 / 1979$.

\begin{tabular}{|c|c|c|c|c|c|c|}
\hline \multirow{2}{*}{ Cidades } & \multicolumn{2}{|c|}{ Masculino } & \multicolumn{2}{|c|}{ Feminino } & \multicolumn{2}{|c|}{ Total } \\
\hline & $\mathrm{N}^{\circ}$ & $\%$ & N. ${ }^{\circ}$ & $\%$ & N. ${ }^{\circ}$ & $\%$ \\
\hline $\begin{array}{l}\text { Campinas } \\
\text { Guaratinguetá } \\
\text { Leme } \\
\text { Lins } \\
\text { Sumaré } \\
\text { Suzano }\end{array}$ & $\begin{array}{l}30 \\
15 \\
30 \\
17 \\
23 \\
60\end{array}$ & $\begin{array}{l}46,2 \\
53,6 \\
61,2 \\
41,5 \\
45,1 \\
53,6\end{array}$ & $\begin{array}{l}35 \\
13 \\
19 \\
24 \\
28 \\
52\end{array}$ & $\begin{array}{l}53,8 \\
46,4 \\
38,8 \\
58,5 \\
54,9 \\
46,4\end{array}$ & $\begin{array}{r}65 \\
28 \\
49 \\
41 \\
51 \\
112\end{array}$ & $\begin{array}{r}18,8 \\
8,1 \\
14,2 \\
11,8 \\
14,7 \\
32,4\end{array}$ \\
\hline Total & 175 & 50,6 & 171 & 49,4 & 346 & 100,0 \\
\hline
\end{tabular}

cido realmente está beneficiando o grupo ao qual se destina ou apenas contribuindo para a família adquirir menos alimentos. O estudo de Beaton e Ghassemi ${ }^{1}$ faz referência ao suplemento alimentar como substituto de parte da alimentação de casa; ainda que esse suplemento se destine somente às crianças, pode provocar modificações no comportamento da família quanto a alimentação do beneficiário ou no da própria criança.

O CEAPE tem, como uma de suas atividades, proporcionar suplementação alimentar ao pré-escolar matriculado e, como visa a educação alimentar da mãe, foi de interesse conhecer se a merenda representa, na realidade, suplemento ou substituto na ingestão alimentar habitual da criança em sua casa.

Tendo em vista que o valor energético e protéico da merenda é aspecto fundamental no comportamento do pré-escolar em relação às refeições de casa, pela maior ou menor saciedade que esse suplemento oferece, os dados foram analisados separadamente por cidade. Procurou-se, ainda, averiguar possíveis diferenças relativas a esse comportamento entre as crianças que frequientavam o CEAPE no período matutino e no vespertino.

Em Campinas, o CEAPE funcionava à tarde: foram investigados 65 pré-escolares, verificando-se que $46,2 \%$ deles apresentaram modificações em seu comportamento quanto às refeições de casa (Tabela 2). Entre essas crianças que modificaram seus hábitos, 20 delas reduziram a quantidade dos alimentos ingeridos e/ou eliminaram refeições, das quais 16 tiveram ingestão insuficiente de calorias. Ainda que 10 pré-escolares aumentassem a quantidade de alimentos nas várias refeições do dia, a metade deles mostrou dieta inade- 


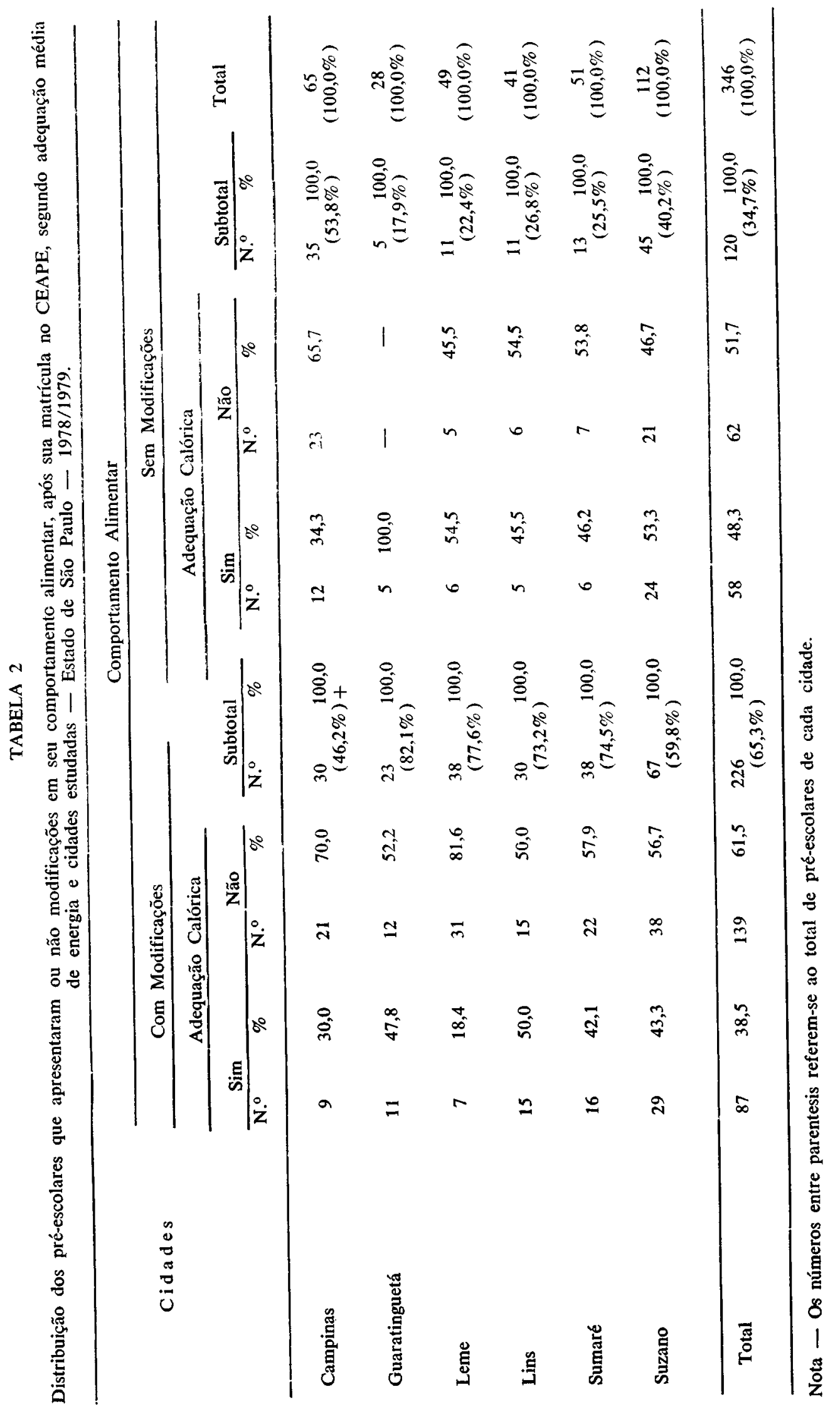


quada em energia e, daqueles (35) que nada alteraram, 23 também tiveram alimentação deficiente em calorias. A exclusão do lanche da tarde, de casa, foi expressiva, 40,5\%. Essa condição era pouco esperada, considerando-se o horário de permanência da criança no CEAPE (de 13:30 às 14:30 h) e o baixo poder de saciedade da merenda servida. Por esses mesmos motivos, também não deveria ocorrer diminuição na quantidade de alimentos ingeridos no almoço e no jantar, fato que se verificou. Deve ser ressaltado que, em Campinas, resultados de pesquisa sobre o consumo alimentar do grupo de pré-escolares, mostrou alta proporção de dieta caloricamente inadequada $(67,7 \%)^{9}$. Essas crianças são provenientes de área peri-urbana, carente de todos os recursos assistenciais, para as quais o CEAPE deveria proporcionar atendimento global, segundo sua filosofia. Entretanto, com apenas uma hora de permanência da criança no CEAPE, não há possibilidade de serem desenvolvidas muitas atividades, sendo esse horário quase totalmente preenchido pela distribuição e consumo da merenda. Acresce, ainda, que esta se mostrou de baixo valor calórico, não constituindo, assim, um suplemento no dia alimentar das crianças, face ao percentual expressivo de pré-escolares que reduziram o volume da ingestão de alimentos e/ou eliminaram refeições. E possível que a família não tivesse preocupação quanto a alimentação desse grupo, uma vez que as crianças recebiam a merenda no CEAPE.

Em Guaratinguetá, os dois CEAPEs funcionavam na mesma Escola de primeiro grau, um no período matutino e outro, no vespertino. Dos 28 pré-escolares da amostra, 17 frequientavam o CEAPE no período da tarde. Foi entre estes que se verificou alterações relativas ao lanche e jantar, enquanto que aquelas relacionadas com o almoço referiram-se às crianças do periodo da manhā. Ainda, 18 crianças diminuíram a quantidade dos alimentos ingeridos e/ou excluíram refeiçōes, constatando-se que, delas, 11 apresentaram ingestão calórica insuficiente?. E de notar que, dentre os 5 pré-escolares que não alteraram os seus hábitos alimentares, quanto a quantidade de alimentos ou ao número de refeiçōes, o consumo energético foi adequado (Tabela 2). Para esse grupo a merenda constituiu realmente suplemento, embora não fosse tão elevado o seu teor calórico, nem a sua contribuição no consumo efetivo do pré-escolar. Entretanto, o teor protéico da merenda foi elevado, preenchendo $21,4 \%$ das recomendaçōes para essa faixa etária.
Em Leme, dos 49 pré-escolares amostrados, 36 frequientavam o periodo da manhã. Pertencem ao grupo, tanto os pré-escolares que reduziram a quantidade de alimentos ingeridos no almoço quanto aqueles que substituíram essa refeição por lanche e/ou a excluíram de seu dia alimentar. Essas crianças totalizam 27 e representaram proporção bastante elevada $(55,1 \%)$ de pré-escolares que tiveram mudanças no almoço, uma das principais refeições do dia, entre nós. Dentre esses pré-escolares do período matutino, um diminuiu a quantidade de alimentos no jantar.

Dos 28 pré-escolares que diminuíram a sua ingestão alimentar total diária e que frequientam o CEAPE no período da manhã, 22 mostraram ter dieta insuficiente em calorias. São deste horário matutino também as crianças que incluíram o lanche da tarde em seu dia alimentar, apresentando, contudo, inadequado consumo calórico.

As alterações referentes a exclusão e/ou diminuição de alimentos no jantar, bem como à exclusão do lanche foram encontrados entre pré-escolares do período vespertino; de 8 pré-escolares, constatou-se que 7 não ingeriam alimentação suficiente em calorias. Notou-se, ainda, que mesmo entre as crianças que não modificaram o seu comportamento alimentar (11), dos dois períodos, 5 mostraram ingestão deficiente em energia. Assim, em Leme, verificou-se que dos 49 pré-escolares estudados, 36 nāo ingeriram dieta caloricamente suficiente (Tabela 2).

Considerando-se a merenda servida nos CEAPEs de Leme, que se mostrou de baixo teor calóricos, deduz-se que a sua contribuição como suplemento calórico na ingestão dos pré-escolares é reduzida.

Na cidade de Lins, a pesquisa abrangeu 41 pré-escolares, matriculados em dois CEAPEs que funcionam no período vespertino, porém em locais diferentes. Das 17 crianças que reduziram o volume dos alimentos ingeridos e/ou excluíram refeiçōes, 8 consumiram dieta adequada em calorias. Alimentação deficiente em energia foi verificada também entre os pré-escolares que aumentaram a quantidade dos alimentos consumidos (13) e entre aqueles que em nada modificaram suas refeiçōes (11); assim, a proporção de pré-escolares com dieta inadequada em energia foi de $53,8 \%$ e $54,5 \%$, respectivamente.

A merenda de Lins apresentou, entre todas, - maior valor médio energético" contribuindo com $24,4 \%$ da ingestão calórica diária do pré- 
-escolar e, ainda assim, o percentual de crianças com dieta inadequada (com ou sem modificaçōes) foi de $51,2 \%$ do grupo estudado. Nota-se, pois, que as crianças dos CEAPEs, das duas diferentes áreas, têm alimentação deficiente em energia.

Em Sumare, dois CEAPEs funcionavam no período da manhã e outro, em horário intermediário, de 10:30 às 13:30 horas. Dos 51 pré-escolares estudados nesse Município, 21 freqüentavam o CEAPE no horário intermediário; destes, 11 diminuíram a quantidade dos alimentos ingeridos em casa em uma ou mais refeições e/ou as excluíram de seu dia alimentar, dos quais 8 não consumiram dieta caloricamente adequada. Entre os que em nada modificaram sua alimentação, 7 apresentaram o consumo insuficiente de calorias (Tabela 2).

Dentre os pré-escolares que excluíram o almoço, 11 freqüentavam o CEAPE no período da manhã. Exclusāo de almoço seria esperada entre aqueles que vão ao Programa no horário intermediário, levando-se em conta que a merenda coincide com a hora em que a criança estaria almoçando em seu lar, aproximadamente, de 11:00 às 11:30 horas. Entretanto, do grupo desse período, apenas 6 deixaram de almoçar. Ainda que não fosse elevado o percentual de pré-escolares que excluíram o lanche da tarde $(15,8 \%)$, não deveria ser constatada tal situação, considerando-se que essas crianças estão em seu lar no horário em que habitualmente tomavam essa refeição, antes de se matricularem no Programa. Dentre os pré-escolares de todos os CEAPEs de Sumaré verificou-se que 38 reduziram a quantidade de alimentos e/ou eliminaram refeições, constatando-se que 22 deles apresentaram dieta insuficiente em energia (Tabela 2). O teor calórico da merenda de Sumaré não foi dos mais baixos, proporcionando $21,8 \%$ da ingestão média energética do grupo; porém, seu conteúdo em proteína total foi mais elevado que nas cidades restantes, bem como em proteína animal.' Note-se que a contribuição da merenda para satisfazer às recomendações protéicas diárias do pré-escolar foi de $32,3 \%$, percentual mais alto de todos municipios estudados (Mazzilli1 ${ }^{10}$ ).

Em Suzano, dos 112 pré-escolares estudados, $96(85,7 \%)$ estavam matriculados nos três CEAPEs que funcionavam à tarde. Entre essas 96 crianças, 46 reduziram o volume das refeiçōes e/ou as eliminaram de sua alimentação diária. É neste grupo que estão incluídos os pré-escolares que deixaram de tomar o lanche em sua casa; para estes a merenda foi substituto da refeição do lar. Deve ser men- cionado que 28 crianças tiveram ingestão deficiente em energia, entre aquelas que reduziram o volume de alimentos e/ou excluíram refeições de seu dia alimentar.

Entre os pré-escolares que freqüentavam o período da tarde (16), apenas 3 diminuíram a quantidade de alimentos ingeridos e/ou eliminaram refeições, sendo que 2 apresentaram dieta caloricamente adequada. Ressalta-se que, dentre as crianças que em nada alteraram a sua alimentação (9), 5 tiveram ingestão insuficiente em calorias, bem como entre aqueles que aumentaram a quantidade de alimentos e/ou incluíram refeiçōes (4), metade mostrou inadequação energética em sua dieta. Notou-se também que, no grupo que não sofreu nenhuma alteração em seus hábitos alimentares (45), a proporção de pré-escolares com dieta insuficiente em calorias correspondeu a $46,7 \%$ (Tabela 2).

O valor médio calórico das merendas servidas nos CEAPEs de Suzano foi de 308 calorias, o que equivaleu a $17,2 \%$ da ingestão média total dos pré-escolares 9 . Essa contribuição não foi o menor valor verificado na amostra estudada, mas, comparando-se com o que esse suplemento deveria proporcionar, está bem abaixo e mostrou não ser suficiente para complementar a dieta daquelas crianças que continuaram a ingerir a mesma quantidade de alimentos e o mesmo número de refeiçōes em seu lar.

Englobando-se os resultados apresentados, separadamente por cidade, constatou-se que:

- $178(51,4 \%)$ pré-escolares amostrados reduziram a ingestão alimentar de casa, mediante exclusão de refeições e/ou diminuição da quantidade de alimentos habitualmente ingerida, após receberem a merenda no CEAPE. Dessas crianças, $115(64,6 \%)$ apresentaram consumo insuficiente de calorias.

Pelos resultados encontrados parece que, apesar de seu baixo valor energético, a merenda está interferindo negativamente na alimentação do lar dos pré-escolares estudados, tanto em relação à quantidade de alimentos, quanto ao número de refeições que a criança recebe em casa. Esses resultados estão em concordância com os achados de Beaton e Ghassemi $^{1}$ que, analisando cerca de 200 estudos sobre programa de suplementação alimentar, referem ser frequiente uma redução compensatória no consumo de outros alimentos, após a ingestão do suplemento. Mas, se assim for, a merenda não está cumprindo o seu papel de suplemento - aumentar o fornecimento de 
energia e de nutrientes - que, por erro de interpretação familiar, pode reduzir a oferta de alimentos em casa, diminuindo seu efeito benéfico.

Para visualisar melhor as alterações verificadas no comportamento alimentar do pré-escolar, isoladamente por refeição, é apresentada a Tabela 3. Nela pode-se notar que o número de modificações que prejudicam a ingestão de alimentos da criança é muito maior que 0 número de mudanças que beneficiam o seu consumo alimentar diário. A influência dessas modificações sobre a adequação calorica da dieta dos pré-escolares pode ser analisada na Tabela 2; observe-se que 0 percentual de criança que alterou o seu comportamento alimentar é mais elevado, bem como o daquelas que mostraram insuficiente ingestão energética.

A maior mudança que se constatou, em proporção, refere-se à substituição do lanche de casa pela merenda servida aos pré-escolares que frequientam o CEAPE no período da tarde. Talvez essa modificação fosse até esperada, considerando-se que há coincidência entre o horário em que a criança costumava tomar o seu lanche em casa e aquele em que recebe a merenda no Programa. Entretanto, verificando-se que $60,4 \%$ das crianças continuaram tomando essa refeição no lar (Tabela 3), é possivel que a exclusão do lanche decorra do comportamento da família, julgando-o desnecessário em casa, uma vez que a criança já recebera a merenda no CEAPE. Tendo em vista que o CEAPE é programa educativo e proporciona esclarecimento aos responsáveis e às mães inscritas sobre a finalidade da merenda na alimentação da criança, os resultados desta pesquisa sugerem que se torna imperioso reforçar a orientação da família sobre a importância da criança não mudar seus hábitos alimentares, quanto à quantidade de alimentos e ao número de refeições ingeridas no lar. E preciso enfatizar que a merenda oferecida, durante a permanência do pré-escolar no Programa, visa a suplementar a dieta e não a substituir nenhuma das refeições que a criança costumeiramente ingere em casa.

- Dos pré-escolares investigados, 48 (13,9\%) aumentaram a quantidade de alimentos ingeridos habitualmente $\mathrm{e} / \mathrm{ou}$ incluíram refeições; destes, $23(47,9 \%)$ mostraram ingestão calórica inadequada.

- Das crianças estudadas, $120(34,7 \%)$ não mostraram nenhuma alteração quanto às refeiçōes: entre elas, $62(51,7 \%)$ tiveram alimentação deficiente em energia.

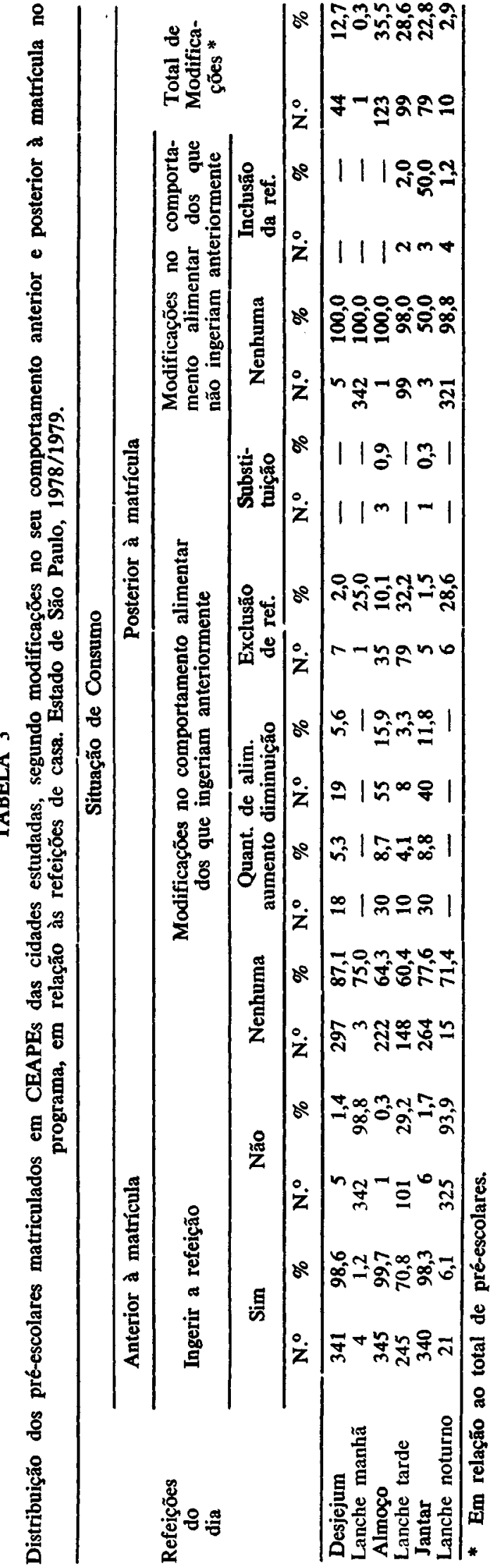


Pelos resultados, que mostraram existir inadequação calórica na dieta de percentagem expressiva das crianças amostradas, constatou-se que a merenda, embora seja insatisfatória quanto à energia, vitaminas e minerais, constitui, ainda assim, um suplemento na sua alimentação, principalmente no que se refere a proteínas. Estas, além de representarem $14,4 \%$ a $32,3 \%$ do consumo protéico total diário do pré-escolar, são qualitativamente satisfatórias.

Ainda que pouco se tenha pesquisado sobre o real papel da suplementação da merenda na ingesãto total diária da criança, não se julgaria sensato suspendê-la, uma vez que, certamente, a situação alimentar dos pré-escola. res deste estudo seria pior, não fosse a contribuição da merenda.

Aspecto que merece ser enfatizado diz respeito à orientação da família, no sentido de que não modifique o padrão habitual de refeições no lar, a fim de que o suplemento alimentar, no caso, a merenda, constitua efetivamente uma fonte adicional de energia e nutrientes no dia alimentar da criança, para que seja cumprida sua finalidade precípua: melhorar o estado nutricional do pré-escolar.

\section{CONCLUSOEES}

- Dos 346 pré-escolares amostrados, 65,3\% (226) modificaram seu comportamento ali- mentar, após passarem a receber o suplemento no CEAPE.

- Dentre as 226 crianças com modificações em seu comportamento alimentar, $78,8 \%$ (178) reduziram sua ingestão diária, mediante diminição da quantidade de alimentos e/ou exclusão de refeiçōes habitualmente ingeridas no lar, das quais $64,6 \%$ (115) tiveram sua dieta insuficiente em energia.

- A substituição, diminuição e/ou exclusão de refeições de casa foram elevadas: esse fato sugere falta de informação da família sobre a finalidade da merenda, que visa a suplementar a dieta de casa e não a substituir refeições.

\section{RECOMENDAÇOESS}

- Considerando os resultados, recomenda-se que seja incluída, nos programas de suplementação alimentar, orientação à família sobre a finalidade da merenda na dieta do pré-escolar, destacando seu papel de suplemento e não de substituto das refeiçōes de casa.

- Recomenda-se que os programas de suplementação alimentar sejam baseados em pesquisas prévias de consumo de alimentos, a fim de se contar com informações essenciais, tanto para os executores dos programas, quanto à orientação da própria família do beneficiário.

MAZZILLI, R. N. [School-lunch as part of the eating habits of children enrolled in Pre-school Education and Feeding Centers]. Rev. Saúde públ., S. Paulo, 21:317-25, 1987.

ABSTRACT: It was studied the role of the school lunch in the dietary behaviour of the three hundred and forty-six preschool children drawn from the Preschool Education and Feeding Centre (CEAPE), in six towns of the State of S. Paulo, Brazil. In home entreviews, the mothers or persons responsible for the preschool children's diet gave the number of meals and the quantity of their food intake before and after their participation in the Program. It was noted that the school lunch as interfered in the dietary intake of children insofar as quantity of food and number of meals usually eaten at home is concerned. The results showed that one hundred and seventy-eight $(51.4 \%)$ preschool children decrease their dietary intake at home, through excluding meals and/or by reducing the quantity of food, after eating the school lunch; of the total of these children, one hundred and fifteen $(64.6 \%)$ pre-school children showed inadequate diet as regards energy intake; forty-eight (13.9\%) children increased the quantity of usual foods and/or included meals in their diet, but twenty-three children (47.9\%) showed insufficient energy intake. Among the one hundred and twenty $(34.7 \%$ ) preschool children that did not show any modification in their diet, sixty-two $(51.7 \%)$ showed inadequate energy intake. We may conclude that it is necessary to inform the family that the role of the school lunchis as a dietary supplement and not a substitute for meals eaten at home.

UNITERMS: School feeding. Child, preschool. Food habits. Feeding behavior. Caloric intake. Nutrition education. 


\section{REFERENCIAS BIBLIOGRĀFICAS}

1. BEATON, G. H. \& GHASSEMI, H. Suplementary feeding programes for young children in developing countries: report prepared for UNICEF, and the ACC sub-Committee on Nutrition of the United States. [s.1.p.] 1979 [Mimeografado].

2. FLORES, M. Perfiles dietéticos según el nivel socioeconomico en Honduras. Arch. lat.-amer. Nutr., 26:401-23, 1976.

3. FLORES, M. et al. Annual patterns of family and children's diet in the three Guatemalan indian communities. Brit. J. Nutr., 18:281-3, 1964.

4. FLORES, $M$. et al. Relacion entre la ingesta de calorias y nutrientes en preescolares y la disponibilidad de alimentos en la familia. Arch. lat.-amer. Nutr., 20:41-58, 1970.

5. FLORES, M. et al. Dieta del pre-escolar en la área rural de El Salvador. Arch. lat.-amer. Nutr., 22:205-25, 1972.

6. GANDRA, Y. R. Asistencia alimentaria por medio de Centros de Educacion del Pre-Escolar. Bol. Ofic. sanit. panamer, 74:302-14, 1973.

7. GANDRA, Y. R. O pré-escolar de dois a seis anos de idade e o seu atendimento. Rev. Saúde públ., S. Paulo, 15 (Supl.):3-8, 1981.

8. INSTITUTO NACIONAL DE ALIMENTAÇÃO E NUTRIÇÃO. Programa Nacional de Alimentação e Nutrição (PRONAN II). Brasília, 1976. (Doc. Tecn. 06).

9. MAZZILLI, R. N. \& GANDRA, Y. R. Consumo alimentar de pré-escolares matriculados nos Centros de Educação e Alimentação de
Pré-Escolares (CEAPEs) e de suas respectivas famílias. Rev. Saúde públ., S. Paulo, 15 (Supl.):23-32, 1981.

10. MAZZILLI, R. N. Valor nutricional da merenda e sua contribuição para as recomendações nutricionais do pré-escolar, matriculado em CEAPE. Rev. Saúde públ., 21:246-54, 1987.

11. MENCHU, M. T. et al. Efecto del nivel socioeconomico de la familia sobre la dieta del niño escolar. Arch. lat-amer. Nutr., 23:305-23, $1,973$.

12. MINISTERIO DA EDUCAÇÃO E CULTURA. Campanha da Merenda Escolar. Cartilha de merenda escolar: $1 .^{\circ}$ caderno. $2 .^{\mathrm{a}}$ ed. Rio de Janeiro, 1956.

13. MINISTERIO DA EDUCAÇÃO E CULTURA. Programa Nacional de Alimentação do Escolar - PNAE: uma abordagem técnica. Brasília, 1982. [Mimeografado].

14. MORGAN, J. The dietary survey and the asses'ment of food intake in the preschool child: a review. J. hum. Nutr., 34:376-81, 1980.

15. ROSENBURG, C. P. Merenda escolar e crescimento. São Paulo, 1972. [Tese de Doutoramento - Faculdade de Saúde Pública da USP].

16. WALKER. A. R. P. \& RICHARDSON, B. D. Are school meals necessary? $S$. Afr. med. J., 53:229-30, 1978.

Recebido para publicação em 7/11/1985 Reapresentado em 13/2/1987

A provado para publicação em 21/3/1987 